\title{
THE VANCOUVER OBSESSIONAL COMPULSIVE INVENTORY (VOCI)
}

\author{
Dana S. Thordarson, ${ }^{a^{*}}$ Adam. S. Radomsky, ${ }^{b}$ S. Rachman, ${ }^{a}$ \\ Roz Shafran, ${ }^{c}$ Craig N. Sawchuk, ${ }^{d}$ and A. Ralph Hakstian ${ }^{a}$
}

${ }^{a}$ Department of Psychology, University of British Columbia, 2136 West Mall, Vancouver BC V6T 1Z4, Canada

${ }^{\mathrm{b}}$ Department of Psychology, Concordia University, 7141 Sherbrooke St W, Montreal QC H4B 1R6, Canada

${ }^{\mathrm{c}}$ Department of Psychiatry, University of Oxford, Warneford Hospital, Oxford, OX3 7JX, United Kingdom

${ }^{\mathrm{d}}$ Department of Psychiatry and Behavioral Sciences, University of Washington Medical Center, 4225

Roosevelt Way NE, Seattle WA 98105, USA

${ }^{*}$ Corresponding author. Dr. Thordarson is now at the Department of Psychiatry, University of British Columbia, 2255 Wesbrook Mall, Vancouver BC V6T 2A1, Canada. Tel.: +1-604-822-8030; Fax: +1-604822-7756, Email danat@interchange.ubc.ca.

Keywords: Obsessive Compulsive Disorder, Test Construction, Questionnaires, Self Report, Psychological Assessment 


\begin{abstract}
The original Maudsley Obsessional Compulsive Inventory $(\mathrm{MOCl})$ has been widely used and is considered to be one of the best available self-report instruments for measuring observable obsessivecompulsive problems such as washing and checking. However, it has several limitations and requires updating. Our revision of the $\mathrm{MOCl}$, the Vancouver Obsessional Compulsive Inventory (VOCI), was designed to provide assessment of a range of obsessions, compulsions, avoidance behaviour, and personality characteristics of known or theoretical importance in obsessive-compulsive disorder (OCD). The development of the $\mathrm{VOCl}$ is described, and we provide evidence of its reliability and validity. Our findings in samples of people with OCD, people with other anxiety disorders or depression, community adults, and undergraduate students suggest that the $\mathrm{VOCl}$ is a promising new measure. We anticipate that, like its predecessor, the VOCI will have widespread use in both research and clinical settings.
\end{abstract}




\section{Introduction}

The MOCl (Hodgson \& Rachman, 1977) is a widely used self-report instrument for measuring observable compulsive behaviour such as washing and checking. It contains 30 true/false items, with subscales for cleaning, checking, doubting/conscientiousness, and obsessional slowness. Over the past twenty-five years, the $\mathrm{MOCl}$ has demonstrated adequate internal consistency, with good criterion, convergent, and discriminant validity (e.g., Emmelkamp, Kraaijkamp, \& van den Hout, 1999; Richter, Cox, \& Direnfeld, 1994). Despite its longevity as a clinical research instrument with sound psychometric properties, the $\mathrm{MOCl}$ has several limitations, and requires modernizing as it was constructed in the "precognitive era." First, the slowness subscale has been criticized as being neither internally consistent nor factorially distinct (Emmelkamp, 1988; Taylor, 1998). Second, assessment of obsessive-compulsive phenomena other than washing and checking is limited (e.g., obsessions, hoarding, covert rituals). Third, although originally designed as a research instrument, it has often been used to assess therapeutic change; however, the $\mathrm{MOCl}$ is not well suited to measuring changes with treatment, both because of its dichotomous response format, and because several items refer to past and permanent events rather than current behaviour and concerns (e.g., My parents were rather strict). Finally, in order to control for the confounding effects of response set, which was a major but exaggerated concern in 1977, half the items in the $\mathrm{MOCl}$ were negatively worded; since a number of items are worded as double negatives, patients often complain that they are difficult to understand, and scoring can be confusing.

Other self-report measures of OCD-related thoughts and behaviour also have drawbacks. The original Padua Inventory (Sanavio, 1988) contained four subscales: checking, contamination fears, mental dyscontrol, and fear of behavioural dyscontrol. Several items were found to be measuring worry rather than obsessions, and the scale was revised by Burns, Keortge, Formea, and Sternberger (1996). Their revised scale, the Padua Inventory-Washington State University Revision, comprised five subscales: obsessional thoughts about harm to oneself or others, obsessional impulses to harm oneself or others, contamination obsessions and washing compulsions, checking compulsions, and dressing and grooming compulsions. The revised Padua Inventory has good psychometric properties and is one of the most comprehensive self-report measures of OCD, but several important groups of symptoms are not covered, such as hoarding. The Obsessive-Compulsive Inventory (OCl; Foa, Kozak, Salkovskis, Coles, 
\& Amir, 1998) is a newer inventory that assesses the frequency and distress associated with washing, checking, doubting, ordering, obsessing, hoarding, and mental neutralizing. However, both patients and clinicians have expressed some difficulty with the rating requirements of the $\mathrm{OCl}$, as each item is rated on two dimensions (frequency and distress). Some patients report that this double-rating is somewhat confusing and repeatedly ask for information about how to complete the scale, while others simply take a very long time to complete it. Given that patients with OCD are often extremely slow at completing questionnaires (Rachman \& Hodgson, 1980), it would be preferable to administer a questionnaire without a double-rating requirement.

Our revision of the $\mathrm{MOCl}$, the Vancouver Obsessional Compulsive Inventory ( $\mathrm{VOCl}$ ) was designed to provide assessment of a wider range of obsessions, compulsions, avoidance behaviour, and personality characteristics of known or theoretical importance in OCD, and to refine it in the light of developments over the past two decades. Each item is rated on a 5-point Likert-type scale to enhance its sensitivity to therapeutic change. All items refer to current concerns and behaviour, and are positively cued, leading to easier administration, scoring, and interpretation. The development of the new scale began in 1994, and followed a construct-based approach through several stages of development, including both factor- and item-analytic strategies. Importantly, the scale is expanded beyond its original behaviourist basis and now includes cognitive items.

\section{Development of the $\mathrm{VOCl}$}

\subsection{Phase 1}

S. Rachman and Steven Taylor devised a pool of 172 items, organized into 13 content domains relevant in OCD. The item pool was administered to 183 undergraduate students. A principal components analysis of each section was used to reduce the item pool by extracting the best items from each content domain. Results of this analysis suggested partitioning some sections into two factors while collapsing other domains into a single scale. An 84-item preliminary scale emerged, comprising 17 internally consistent subscales. Because of the large number of subscales, the subscales were arranged logically into four clusters: Contamination, Danger, other Obsessions and Compulsions, and Personality Characteristics. This scale was named the Maudsley Obsessional Compulsive Inventory - 
Revised (MOCl-R), with the psychometric properties presented in 1995 (Rachman, Thordarson, \& Radomsky, 1995).

\subsection{Phase 2}

The 84 -item MOCI-R was distributed to 272 undergraduate students, 122 community adults, 118 people who reported that they had received a diagnosis of OCD, and 55 people who identified themselves as having other anxiety disorders (mostly panic disorder). Our analysis of these data suggested that the questionnaire required further revision. In particular, some subscales failed to discriminate between people with OCD and either students or anxiety control subjects. This finding stood in marked contrast to the good known-groups validity of the original $\mathrm{MOCl}$. Furthermore, an arrangement of 17 subscales and four clusters was clearly too unwieldy for a succinct final scale. With these issues in mind, we substantially revised the 84 -item version.

First, we examined the factor structure of the $84 \mathrm{MOCl}-\mathrm{R}$ items, along with the 30 original $\mathrm{MOCl}$ items, in the sample of OCD sufferers. Given the large number of items (114) and the relatively small sample size $(N=118)$, these results must be considered tentative, as the results of factor analysis can be unreliable without a high subjects-to-variables ratio. An unweighted least squares common-factor analysis on the basis of 7 factors, with direct oblimin transformation, yielded a clear and interpretable solution. The following factors emerged: Checking, Contamination, Indecisiveness/Perfection/Concern with Mistakes, Obsessions, Routine/Slowness/Counting, and two thought-action fusion (TAF) factors, TAF-Moral (beliefs that bad thoughts are morally as unacceptable as bad actions), and TAF-Likelihood (beliefs that having a thought about something terrible happening increases the risk of it actually happening) (see Rachman, Thordarson, Shafran, \& Woody, 1995).

Items loading on the two TAF factors were removed from subsequent scale revisions for a

number of reasons. We wanted to make the new questionnaire more tightly focused on OCD complaints (most of the items refer to obsessions, compulsions, and avoidance); the TAF items, being the only items referring to beliefs, did not fit well with the rest of the scale, and may have contributed to difficulties with its factor structure. Furthermore, in view of the content domain of potential beliefs and appraisals associated with OCD, it did not make sense to retain only TAF-related beliefs. Finally, we decided to 
construct a separate scale to independently measure this belief domain (TAF Scale; Shafran,

Thordarson, \& Rachman, 1996). Therefore, from the 7-factor solution reported in the previous paragraph, the two TAF factors were removed.

The best items from the five remaining factors (Checking, Contamination, Indecisiveness/ Perfection/Mistakes, Obsessions, Routine/Slowness/Counting) were selected to form five new subscales. Items were selected on the basis of (a) their absence of factorial complexity, (b) their discrimination between (i) people with OCD and (ii) anxious, community adult, and student groups, and (c) their high corrected item-total correlations, within the existing data set. A number of items were rewritten to make them more clearly reflect pathology, in an attempt to improve their ability to discriminate among the groups. In particular, some items were rewritten to conform more closely to the original $\mathrm{MOCl}$ items, especially those $\mathrm{MOCl}$ items that discriminated well among the groups. A new set of items that represented hoarding, which was not initially included in the scale's development, was added. The resulting scale, now termed the Vancouver Obsessional Compulsive Inventory (VOCl), comprised 52 items.

\subsection{Phase 3}

The purpose of this phase was to make a preliminary assessment of the criterion-related validity of each item and subscale, in preparation for the final validation study. The 52 -item VOCl was sent to approximately 100 members of the Participant Register of the Fear and Anxiety Laboratory at the University of British Columbia (UBC), and was returned by a total of 80 participants (36 reported they had OCD and 44 reported having another anxiety disorder or mood disorder). An additional sample of 214 undergraduate students at UBC completed the questionnaires for subject pool credits. Eight students were excluded from analyses because of significant self-reported psychiatric history.

Mean differences were examined between OCD subjects and the two comparison groups (other anxiety disorder/depression subjects and students) on all subscales and on each item within subscales. An attempt was made to determine whether each subscale was unifactorial in both the student and OCD groups by conducting a principal components analysis of the items within each subscale and examining the scree plot and the first principal component. Finally, within-groups estimates of internal consistency 
(alpha) reliability and corrected item-total correlations were examined. The results of these analyses are described below. Items that were found to perform poorly were replaced with new items. In these cases, replacement items were written based on items contained in other well-established OCD measures, such as the $\mathrm{MOCl}$ and Padua Inventory.

Contamination. This subscale was unifactorial in both student and OCD samples. One item (Touching the floor frightens me) had a very low item-total correlation in both samples, and was infrequently endorsed, even by participants with OCD who reported cleaning compulsions. It was replaced by a different item referring to excessive use of disinfectants, based on an original $\mathrm{MOCl}$ item.

Checking. This was unifactorial in both student and OCD samples. All items showed good discrimination between participants with OCD, students, and participants with other anxiety disorders, and had high item-subscale total correlations. A few items were rewritten to improve their readability.

Obsessions. This was unifactorial in students, but one item formed a single factor in participants with $\mathrm{OCD}$, and had a zero item-subscale total correlation. This item was rewritten.

Hoarding. The hoarding subscale failed to discriminate between OCD and other groups of participants; students in particular scored highly on most items. We revised the hoarding scale thoroughly, developing an expanded content domain based on empirical and theoretical work of Frost and colleagues (e.g., Frost \& Gross, 1993).

Indecisiveness/Perfection/Concern over mistakes. This was unifactorial in both student and OCD participants, with good discrimination among groups. Depressed non-OCD subjects tended to score highly, which is consistent with the fact that indecisiveness is a common feature of depression. Thus, while indecisiveness is characteristic of OCD, there is likely to be true overlap with depression, for which indecisiveness is a diagnostic feature.

Routine/Counting/Slowness. The two items on which depressed participants scored higher than OCD participants were rewritten or replaced.

Following the Phase 3 revisions, the resulting $\mathrm{VOCl}$ contained 55 items. The items were rerandomized in preparation for the final evaluation of the reliability and validity of the $\mathrm{VOCI}$, which is presented in the next section. Nine of the 55 items were identical or nearly identical to $\mathrm{MOCl}$ items (VOCl items 12, 18, 23, 25, 33, 41, 43, 47, and 53). 


\section{Final Validation Study}

In the final validation study, the internal consistency and test-retest reliability of the $\mathrm{VOCl}$ was estimated for both the total scale and each of the six subscales, and for both normal and clinical samples. A variety of information related to construct validity was also gathered:

1. The factor structure within both OCD and normal samples was examined.

2. The criterion-related (known-groups) validity was evaluated in two ways. First, the scores of OCD sufferers were compared with anxiety/depression control and community adult and student participants. Secondly, OCD participants were coded as to whether they had problems in each of five OCD symptom domains (contamination/cleaning, checking, hoarding, repugnant obsessions, and ordering/repeating), based on the main OCD themes reported by the interviewer. VOCl subscale scores of OCD participants with problems in each domain were compared with the subscale scores of OCD participants who did not have concerns in that particular domain.

3. The convergent and discriminant validity of the $\mathrm{VOCl}$ was evaluated, by correlating it with other measures of OCD, measures of other problems (depression, anxiety, worry), and personality traits (neuroticism, psychoticism, extraversion). It was hypothesized that, while the $\mathrm{VOCl}$ would be positively correlated with depression, anxiety and worry due to true construct overlap, stronger correlations were expected to emerge with other measures of $O C D$, especially the $\mathrm{MOCl}$ and revised Padua Inventory.

\subsection{Method}

\subsubsection{Participants}

$O C D$. The OCD sample consisted of 88 adults with a diagnosis of OCD. The diagnosis was confirmed by a structured diagnostic interview. The majority of participants (91\%) had a primary diagnosis of OCD; the rest had OCD symptoms significant enough to warrant clinical diagnosis, but also had comorbid conditions (e.g., major depressive disorder) that were rated as more severe. Participants were recruited from several sources: Participant Register of the Fear and Anxiety Laboratory in the Department of Psychology, UBC $(N=23)$; a treatment study of OCD in Traumatic Stress Clinic, 
Department of Psychiatry, UBC ( $N=27)$; a treatment study for OCD at the Anxiety Disorders Unit, UBC Hospital $(N=32)$; and Harbor View Mercy Hospital, Arkansas $(N=6)$. The VOCI was included in the standard questionnaire packages being offered as part of the established research protocol at each site. As a result, most participants did not complete the entire battery of measures described below. For each analysis, the relevant $\mathrm{Ns}$ are reported as they vary depending on the measures and samples involved.

Demographic statistics for the samples are presented in Table 1. Forty-six OCD participants (52\%) were comorbid for at least one Axis I anxiety or mood disorder: 16 were diagnosed with generalized anxiety disorder, 15 social phobia, 13 current major depressive disorder, 5 specific phobia, 5 panic disorder, 4 posttraumatic stress disorder, 1 panic disorder with agoraphobia, and 1 bipolar I disorder.

Anxiety/Depression (A/D) Controls. The A/D control group consisted of 60 adults with DSM-IV Axis I anxiety or mood disorders other than OCD. Diagnosis was confirmed by a structured diagnostic interview. Participants who met diagnostic criteria for OCD or were considered to have subclinical OCD were excluded. Twenty-nine participants had a diagnosis of current major depressive disorder, 20 panic disorder with agoraphobia, 18 panic disorder, 10 generalized anxiety disorder, 7 social phobia, 6 posttraumatic stress disorder, 2 specific phobia, 3 dysthymic disorder, 1 anxiety disorder not otherwise specified, and 1 bipolar II disorder (frequencies sum to greater than 60 due to comorbidity). Participants came from the same sources as the OCD group: the Participant Register of the Fear and Anxiety Laboratory $(N=24)$; the OCD treatment study in the Department of Psychiatry, $\operatorname{UBC}(N=1)^{1}$; a treatment study for panic disorder (with or without agoraphobia) at the Anxiety Disorders Unit, UBC Hospital ( $N=$ 7 ); and Harbor View Mercy Hospital, Arkansas $(N=28)$. For the same reasons as with the OCD group above, most participants did not complete the entire battery of measures described below, and the Ns for each analysis are reported.

Community Adults. The pool of participants consisted of 42 adults. They included family members, friends, and acquaintances of the Fear and Anxiety Laboratory researchers, as well as friends, family members, and co-workers of participants who distributed additional questionnaires. Of the 42 participants, 5 reported that they were currently suffering from depression, an anxiety disorder, or other mental health problem. Of these five, two reported that their problem was currently causing only slight 
interference in their lives, and these participants were retained. The other three participants reported that their problem caused definite interference in their lives. These three participants were also the only participants in the Community Adults sample who scored above 20 on the Beck Depression Inventory (BDI). As it appeared likely that these three participants were currently suffering from a mood or anxiety disorder, they were excluded from the sample, leaving a group of 39 community adults.

Students. The pool of student participants consisted of 223 psychology undergraduates who completed the questionnaires for subject pool credits. For a portion of the sample, information about current psychiatric problems (including depression and anxiety disorders) was available, but unlike in the adult sample, self-reported psychiatric problems had a poor correspondence with BDI scores. Of the 123 participants for whom this information was available, only 2 reported experiencing problems that definitely or severely interfered with their lives, but an additional 8 participants had BDI scores over 20. Because of this lack of correspondence, and because BDI scores were available for the entire sample, a cut-off score (BDI greater than 20) was used to eliminate participants who were likely to be suffering from emotional problems such as depression. ${ }^{2}$ Using this criterion, 23 participants were eliminated $(10.3 \%$ of the sample), leaving a sample of 200 students.

\subsubsection{Diagnostic Interviews}

The purpose of the diagnostic interview was to establish DSM-IV diagnoses of anxiety and mood disorders, and to rule out psychotic disorders. OCD and A/D control participants were interviewed, using either the Anxiety Disorders Interview Schedule for DSM-IV (ADIS-IV; DiNardo, Brown, \& Barlow, 1994), or the Structured Clinical Interview for DSM-IV Axis I Disorders (SCID-IV; First, Spitzer, Gibbon, \& Williams, 1997). Trained interviewers, all of who were investigators or research assistants in the Anxiety and Fear Laboratory, the Traumatic Stress Clinic, or the Anxiety Disorders Unit, administered the diagnostic interviews.

\subsubsection{Measures Used to Establish Convergent Validity}

Yale-Brown Obsessive-Compulsive Scale (YBOCS) (Goodman et al., 1989). The YBOCS is an interviewer-rated scale that measures the severity of obsessions and compulsions without regard to their 
domain. The YBOCS has excellent interrater reliability with trained interviewers, and good criterionrelated and convergent validity; however, it tends to be highly correlated with depression (see Taylor, 1998, for a review). Trained interviewers administered the YBOCS to most of the participants with OCD. The OCD participants from the treatment study at the Traumatic Stress Clinic were administered a new version of the YBOCS, the DYBOCS (J. F. Leckman et al., unpublished scale), which yields global severity scores in a different metric than the original YBOCS. For the OCD group, the YBOCS or DYBOCS interview provided the means of determining the primary, secondary, and tertiary themes of the obsessional-compulsive problems.

Self-report Yale-Brown Obsessive-Compulsive Scale (YBSR). The self-report version of the YBOCS used in this study consisted of the definitions of obsessions and compulsions from the original YBOCS, space for respondents to write-in any obsessions or compulsions, and the 10 items from the original YBOCS rewritten in a self-report format assessing the severity of the obsessions and compulsions. Several studies have shown that self-report versions of the YBOCS have good reliability and correlate well with the original YBOCS interview scores (Steketee, Frost, \& Bogart, 1996; Warren, Zgourides, \& Monto, 1993).

Maudsley Obsessional Compulsive Inventory (MOCI) (Hodgson \& Rachman, 1977). The MOCI is a 30-item true/false questionnaire assessing OCD symptoms across four domains: Washing, Checking, Doubting/conscientiousness, and Slowness. The total scale as well as the washing and checking subscales have been shown to have good test-retest reliability, internal consistency, known-groups validity, and convergent and discriminant validity (see Taylor, 1998).

Padua Inventory, Washington State University Revision (PI) (Burns, Keortge, Formea, \& Sternberger, 1995). This revised version of the original Padua Inventory (Sanavio, 1988) was used because it was designed to specifically assess obsessions rather than worries. The PI contains 39 items, with 5 subscales: Contamination Obsessions and Washing Compulsions; Checking Compulsions; Dressing and Grooming Compulsions; Obsessional Thoughts about Harm; and Obsessional Impulses to Harm. The PI has demonstrated good internal consistency, test-retest reliability, known-groups validity, and discriminant validity (see Taylor, 1998, for a review). 


\subsubsection{Measures Used to Establish Discriminant Validity}

Beck Depression Inventory (BDI) (Beck \& Steer, 1993a). The BDI is a widely used 21-item selfreport measure of depression. Its reliability and validity have been well established (see Beck, Steer, \& Garbin, 1988).

Beck Anxiety Inventory (BAl) (Beck \& Steer, 1993b). The BAl is a 21-item self-report measure of clinical anxiety. Its validity and reliability have been well established (see Beck, Epstein, Brown, \& Steer, 1988). Recent research suggests that the BAI is particularly useful in measuring symptoms of anxious arousal, rather than worry or tension (Antony, Purdon, Swinson, \& Downie, 1997).

Penn State Worry Questionnaire (PSWQ) (Meyer, Miller, Metzger \& Borkovec, 1990). The PSWQ is a 16-item questionnaire designed to measure the tendency to worry. It is valuable as a discriminating measure, as worries and obsessions have been both conceptually and empirically differentiated in the literature (e.g., Turner, Beidel, \& Stanley, 1992).

Eysenck Personality Questionnaire-Revised (EPQ-R) (Eysenck \& Eysenck, 1983). The EPQ-R in its short form is a 48-item questionnaire that yields measures of the personality traits Neuroticism, Psychoticism, and Extraversion.

\subsubsection{Procedures}

$O C D$ and $A / D$ Control Samples. Participants completed the structured diagnostic interview and YBOCS, if applicable, in the clinic or laboratory. Subjects were then given the questionnaire package to complete at home and return to the clinic on their next visit, or mail to the laboratory in a stamped envelope. A subset of participants with OCD completed the $\mathrm{VOCl}$ again after a test-retest interval ranging from 2 weeks to 3 months, depending on the project.

Community Adults. The community adults were either given the questionnaire in person through family and friends of the researchers, or had questionnaires distributed to their workplaces. Selfaddressed stamped envelopes were provided in which the questionnaire package could be returned anonymously to the laboratory.

Students. Student participants responded to notice-board advertisements of Psychology Subject Pool studies and picked up questionnaire packages at the Fear and Anxiety Laboratory. Participants 
completed the questionnaire packages at their convenience and returned them to the laboratory to receive course credits. Upon returning them to the laboratory, participants who had completed the VOCl at least one week earlier were asked to complete the $\mathrm{VOCl}$ again in the laboratory. We obtained additional test-retest data from participants who participated in a second study through our laboratory. The test-retest interval ranged from 7 to 18 days ( $M=11$ days).

\subsection{Results}

\subsubsection{Missing Data and Outliers}

For all the self-report scales, participants who had valid responses for at least $80 \%$ of the items were given pro-rated scale scores. This approach to missing data prevents the large loss of participants for multivariate procedures. Estimating total scores based on items completed by the participant provides an accurate estimate of participants' true scores provided the scales have high internal consistency. To prevent inflation of estimates of internal consistency, missing data were not replaced at the item level.

Prior to the factor analysis conducted with the OCD sample, one potential outlier was found, and the potential effects of this participant's extreme response to one item were reduced by substituting a less extreme value for the item for this participant for the factor analysis. For the test-retest reliability analysis, two outliers were detected within the sample of students who had completed retest questionnaires; because deleting these outliers had a negligible effect on the test-retest reliability estimates, these cases were retained. For the known-groups validity analysis, several outliers were detected in the $\mathrm{VOCl}$ subscales within the control samples (A/D, adults, and students), but none in the OCD sample. Because deleting these outliers had a trivial effect on the subscale means and the results of the analysis, the outliers were retained to improve the generalizability of the results. In the convergent and discriminant validity analysis, there were no outliers detected on any of the scales within the OCD group. However, the other samples contained several outliers, and deleting the extreme values (retaining the rest of the data from that case) was found to have, at least in some cases, a substantial effect on the size of the correlation coefficients. Therefore, these results were obtained for the data set with outliers deleted. 


\subsubsection{Factor Structure and Examination of Subscales}

A factor analysis of the 55 items of the $\mathrm{VOCl}$ was conducted with the OCD sample $(n=88)$. The results of this factor analysis must be considered provisional, as the low subjects-variable ratio reduced the reliability of the factor loadings. It was not possible to pool the A/D control sample with the OCD sample to increase the number of observations, because the variance-covariance matrices of the two samples were significantly different, based on Box's test $(\underline{M}=4754.31, \underline{F}(1540,44060)=1.66, p<.001)$. The factor analysis was conducted using pairwise deletion of missing data in order to preserve as many observations as possible.

A scree plot of the eigenvalues suggested 5 or 6 factors. Five-, 6-, and 7-factor solutions were obtained using unweighted least squares (MINRES) common-factor analysis, with direct oblimin transformation $(\delta=0)$, and the factor pattern matrices were examined for simple structure and interpretability. In the 5-factor solution, there were seven items with complex factor pattern coefficients (items with coefficients $>.3$ on more than one factor), including three items with coefficients $>.3$ on at least three factors. The factors were easily interpretable, corresponding to contamination, hoarding, obsessions, checking, and a mixed factor of indecisiveness, needing things to look or feel just right, and counting, memorizing, and repeating compulsions. The 6-factor solution had better simple structure, with only two complex items and one item with coefficients $<.3$ on all 6 factors. Again, the factors could be readily interpreted, with the mixed factor resolving into separate factors for (a) needing things to seem just right, and (b) memorizing, repeating and indecisiveness. The 7-factor solution had five complex items, with the same factors as the 6 -factor solution but with counting, memorizing, and bedtime routines as its own factor.

Based on considerations of simple structure and interpretability, we chose the 6-factor solution as the best fit for these data; the primary-factor pattern matrix for this solution is presented in Table 2. The 6-factor solution had good, although not perfect, convergence with the six subscales of the VOCl defined at the previous stage of development. The first factor contained all of the Routine/Counting/Slowness subscale items except for an item describing counting during a routine task. It also included three of the Indecisiveness/Perfection/Concern over Mistakes items, which described perfectionism and attention to detail. It included one Checking item, concerning checking letters before mailing them. Taken together, 
this factor appeared to represent the construct of just right: doing things exactly right, following strict routines, repeating, memorizing, concern with being perfect, and feeling compelled to count. The second factor contained all the Contamination items, plus an item originally from the Obsessions subscale concerning obsessions about illness. The third factor contained the Hoarding items. The fourth factor contained the remaining Obsessions items. The fifth factor contained the remaining Checking items. The sixth factor contained the remaining Indecisiveness items, as well as one Routine item concerning counting during routine tasks.

In summary, the hypothetical factor structure of the $\mathrm{VOCl}$ was largely supported, with clear factors representing Contamination, Checking, Obsessions, and Hoarding. The previous subscales concerning Routine and Indecisiveness were re-organized, with Indecisiveness items concerning perfection and attention to detail now loading with most of the previous Routine items, forming a Just Right factor. Despite the direct oblimin transformation, which permits factors to be as highly correlated as required to yield a factor pattern that best exemplifies simple structure, the 6 factors were not highly correlated; the highest correlation was .33, between the Just Right and Indecisiveness factors (see Table 3). Given the interpretability of this factorial solution, and the sensible re-organization of two of the previous subscales into more coherent factors, we re-organized the subscales based on the current factor analysis. The revised six subscales are Contamination (12 items), Checking (6 items), Obsessions (12 items), Hoarding (7 items), Just Right (12 items), and Indecisiveness (6 items). These six subscales, and the total scale of 55 items, were used for the rest of the reliability and validity analyses. Each item is scored from 0 to 4 , and subscales computed by summing the items for each subscale. The revised subscales with items are presented in Table 4.

\subsubsection{Test-Retest Reliability}

Test-retest reliability estimates are based on 28 students and 28 participants with OCD. The mean test-retest interval for students was 11 days (range 7-18 days); for OCD participants, the mean interval was 47 days (range 9 - 100 days). Test-retest reliability estimates (Pearson $r$ between the first and second administrations) for the $\mathrm{VOCl}$ total scale and subscales are presented in Table 5. The $\mathrm{VOCl}$ and its subscales appear to have excellent test-retest reliability in the OCD sample, with all coefficients .9 
or above, and with the one-sided .95 confidence interval $>.81$ in all cases, despite, on average, a long test-retest interval. For the students, on the other hand, test-retest reliability is poor, ranging from .5 to .6 . In the student sample, these low correlations may be due to range restriction. Most of the students had mean $\mathrm{VOCl}$ item scores between 0 and 1, with the exception of four participants, who appeared to be bivariate outliers. Excluding the four outliers improved the test-retest correlations for some scales (e.g., VOCI total, $r=.62, p<.001$ ), but not others (e.g., VOCl Checking, $r=.44$ ).

\subsubsection{Internal Consistency}

Estimates of the internal consistency of the $\mathrm{VOCl}$ and its subscales were made within each group (OCD, A/D control, adults, students) via coefficient alpha, and are presented in Table 6. The total scale and its subscales appear to have very good internal consistency. The lowest estimates are within the Community Adults sample.

\subsubsection{Known-Groups Validity}

For each scale, we compared the mean score for the OCD sample with the mean for each comparison group, using the Dunnett method of multiple comparisons, with $\alpha<.05$, nondirectional. The OCD group scored significantly higher than the other groups on the VOCl total score, Contamination, Checking, Just Right, and Indecisiveness subscales (see Table 7). The OCD group scored significantly higher than the nonclinical controls but not the A/D control group on the Obsessions and Hoarding subscales.

To examine the ability of the $\mathrm{VOCI}$ to discriminate amongst OCD sufferers with different symptom types, a further known-groups analysis was conducted. Using the main symptoms identified by the YBOCS interviewers, the OCD participants were classified as Cleaners, Checkers, Obsessionals, Orderers, and Hoarders. Because most OCD participants have symptoms in multiple domains, they could be classified as belonging to more than one group. We hypothesized that Cleaners would have higher Contamination scores than non-cleaners in the OCD group; Checkers would have higher Checking scores, Obsessionals would have higher Obsessions scores, Orderers would have higher Just Right scores, ${ }^{3}$ and Hoarders would have higher Hoarding scores than other OCD participants. The 
scores were compared using independent-samples $t$-tests, with a Bonferroni correction for family-wise error rate (as there were 5 domains, the $\alpha$ for each domain was set at .01). The results clearly support the known-groups validity of the Contamination, Checking, Obsessions, and Hoarding subscales (see Table 8). The Just Right subscale, although it distinguished OCD participants from controls, did not appear to distinguish Orderers from other OCD participants.

\subsubsection{Convergent and Discriminant Validity}

The convergent and discriminant validity of the $\mathrm{VOCI}$ were evaluated separately within the OCD and Student samples. Convergent validity of the $\mathrm{VOCl}$ was examined by correlating $\mathrm{VOCl}$ total and subscale scores with other measures of OCD symptom domains ( $\mathrm{PI}, \mathrm{MOCl}, \mathrm{YBOCS}$ scales). To evaluate its discriminant validity, $\mathrm{VOCl}$ total scores were correlated with depression (BDI), anxiety (BAI), worry (PSWQ), and personality variables (Extraversion, Neuroticism, and Psychoticism from the EPQ-R short form). VOCI subscales were correlated with BDI, BAI, and PSWQ, as well as non-corresponding scales from the other OCD scales (PI, MOCI). The results for the OCD sample are shown in Table 9, for the Student sample in Table 10.

$O C D$. The $\mathrm{VOCl}$ total score was highly correlated with the other self-report measures of OCD symptoms (PI total, MOCI total, and YBSR), only moderately correlated with measures of other kinds of psychopathology (BDI, BAI, and PSWQ), and not highly correlated with the personality variables (EPQR). Surprisingly, the $\mathrm{VOCl}$ total score was not highly correlated with YBOCS total score $(r=.14, N=49)$. In this sample, the YBOCS total score was inconsistently correlated with the other measures of OCD; it had a high correlation with YBSR total $(r=.74, N=20)$, a moderate correlation with $\mathrm{MOCl}$ total $(r=.47, N=$ $21)$, and a low correlation with PI total $(r=.22, N=48)$.

As a test of the convergent/discriminant validity of the VOCl total score, the difference between the correlation coefficients for the PI total, MOCI total, YBSR, and BDI were tested using the test to compare two correlated correlation coefficients described in Meng, Rosenthal, and Rubin (1992). ${ }^{4}$ The VOCI-PI correlation was found to be significantly greater than the VOCI-BDI correlation $(z=5.95, p<$ .001), supporting the convergent/discriminant validity of the VOCl. However, the VOCl-MOCl and VOClYBSR correlations were not statistically significantly greater than the VOCI-BDI correlation (at $\alpha=.05)$. 
In the OCD sample, there were high correlations with corresponding or conceptually related subscales in the $\mathrm{PI}$ and $\mathrm{MOCl}$ for most $\mathrm{VOCl}$ subscales. There were relatively smaller correlations between VOCl subscales and noncorresponding subscales of the $\mathrm{PI}$ or $\mathrm{MOCl}$, and $\mathrm{BDI}, \mathrm{BAI}$, and PSWQ. More specifically, VOCI Contamination was highly correlated with $\mathrm{PI}$ Contamination/Washing and $\mathrm{MOCl}$ Washing, and VOCI Contamination was more weakly correlated with BDI, BAI, and PSWQ, and with unrelated subscales of PI and MOCI, except PI Thoughts of Harm. VOCI Checking was highly correlated with PI Checking and $\mathrm{MOCl}$ Checking, had low correlations with BDI, BAI, or PSWQ, and had low to moderate correlations with other subscales of the $\mathrm{PI}$ or $\mathrm{MOCl}$. VOCl Obsessions was highly correlated with the PI scales measuring obsessions of harming (PI Obsessional thoughts of harm and PI Obsessional impulses to harm), and generally had low correlations with unrelated scales except $\mathrm{MOCl}$ checking. VOCI Obsessions was moderately correlated with BDI, BAI, and PSWQ.

The other VOCI subscales (Hoarding, Just Right, and Indecisiveness) do not correspond closely to any of the $\mathrm{PI}$ or $\mathrm{MOCl}$ subscales; nevertheless, they did correlate at least moderately with subscales on related themes. VOCI Just Right correlated with PI Dressing ( $r=.62)$, MOCI Doubting/ Conscientiousness $(r=.62)$ and MOCI Slowness $(r=.51)$. VOCl Just Right was also highly correlated with both $\mathrm{PI}$ and $\mathrm{MOCl}$ Checking, and moderately correlated with $\mathrm{BDI}, \mathrm{BAI}$, and PSWQ. VOCI Indecisiveness was highly correlated with $\mathrm{BDI}(r=.54)$, which may be due to true construct overlap (in fact, indecisiveness is recognized as a symptom of a Major Depressive Episode in the DSM-IV), and was moderately correlated with several other scales, including PI Obsessional thoughts of harm, BAI, PI Checking, MOCl Checking, and PSWQ.

Students. Several outliers were detected within the student sample: 2 participants had $z$ scores > 3.5 for $\mathrm{VOCl}$ contamination, 10 for $\mathrm{VOCl}$ checking, 3 for $\mathrm{VOCl}$ obsessions, 1 for $\mathrm{VOCl}$ just right, 1 for VOCl indecisiveness, 1 for $\mathrm{PI}$ total, 1 for $\mathrm{PI}$ contamination/washing, 2 for $\mathrm{PI}$ dressing/grooming, 2 for $\mathrm{PI}$ checking, 5 for $\mathrm{PI}$ obsessional thoughts of harm, and 5 for $\mathrm{PI}$ obsessional impulses to harm. These scores were deleted for this set of analyses.

The VOCI total score was highly correlated with the PI total $(r=.79)$, and MOCI total $(r=.64)$. However, it was also highly correlated with PSWQ $(r=.58)$ and Neuroticism $(r=.56)$, and moderately correlated with BAI, BDI, and Extraversion. The difference between the correlation coefficients for the PI 
total, $\mathrm{MOCl}$ total, and $\mathrm{BDI}$ were tested as described previously. The $\mathrm{VOCl}-\mathrm{PI}$ and $\mathrm{VOCl}-\mathrm{MOCl}$ correlation coefficients were both found to be significantly greater than the VOCI-BDI correlation $(z=6.13, p<.001$, and $z=3.34, p<.001$, respectively), supporting the convergent/discriminant validity of the VOCl.

There was mixed evidence of convergent/discriminant validity for the $\mathrm{VOCl}$ subscales in the student sample. VOCI Contamination was highly correlated with PI Contamination $(r=.85)$ and $\mathrm{MOCl}$ Washing $(r=.59)$, and had generally low to moderate correlations with other subscales. VOCl Checking was highly correlated with PI Checking $(r=.71)$, and moderately correlated with MOCI Checking $(r=.45)$ as well as several other subscales. VOCl Obsessions was moderately to highly correlated with the obsessions subscales on the PI, but was also moderately correlated with most other scales.

\section{Discussion}

The reliability and validity of the $\mathrm{VOCl}$ and its subscales were, in general, supported by the findings of the present study. The factorial validity of the $\mathrm{VOCl}$ was supported for the Contamination, Checking, Obsessions, and Hoarding subscales, which all emerged as clear factors in the present factor analysis, as they had during the previous phase of development. This was an encouraging result, especially given the relatively small sample sizes available for each analysis, which would tend to reduce the reliability of the factor loadings. The items from two factors identified in the Phase 3 factor analysis, Indecisiveness-Perfectionism-Concern over Mistakes and Routine-Slowness-Counting, loaded on two factors in the final factor analysis, but were arranged differently. Most of the items involving being perfect, paying too much attention to detail, doing things in strict routines, and arranging things perfectly loaded on one factor; items concerning being unable to make trivial decisions loaded on a second factor. These factors were easily interpretable: the first, Just Right, is similar to Leckman et al.'s (1997) Factor 3 (obsessions regarding being perfect, not making mistakes, things having to look or feel just right, and related compulsions of repeating, counting, arranging). The second VOCI factor is a purer indecisiveness factor, which is consistent with the results of Calamari et al.'s (1999) cluster analysis, which elucidated a cluster or subgroup of participants with OCD whose primary concern was "certainty". Because of the improved interpretability of the new factors, the subscales were based on the results of the present factor analysis, and the revised subscales were used in all subsequent analyses. 
There are some remaining concerns, however, regarding the factor structure of the VOCl. First, because of the small sample size in the present analysis, these results must be considered tentative. Repeating the factor analysis in a new sample of OCD participants would almost certainly result in a slightly different factor structure. This would be especially likely for the two new factors described above, which had not appeared in this form in the previous analysis. On the other hand, the other factors (contamination, checking, obsessions, and hoarding) have been essentially replicated (except for a very few items) across the two samples, giving us some confidence in the current factorial solution for these subscales. A replication of the factor analysis will be attempted with a larger data set. The next step will be to attempt to increase the sample size by continuing to accumulate data from OCD participants; once the scale is published we will hope to acquire data from researchers at other centres who are using the scale.

Not addressed in the present study is the issue of the factor structure of the $\mathrm{VOCl}$ in other groups, especially normal populations. For this study we have focused on the factor structure within an OCD population, because we were most interested in the underlying structure of the data within a group that actually suffer from the phenomena in question. It is possible that the factor structure in non-clinical samples would be different; in particular, it may be difficult to detect clear factors for low base-rate obsessional-compulsive phenomena in a non-clinical group.

The internal consistency of the $\mathrm{VOCl}$ subscales was completely adequate in all four samples. The test-retest reliability of the $\mathrm{VOCl}$ subscales in the OCD sample was very high, especially given the long retest interval. Without treatment, obsessive-compulsive symptoms are known to be stable over time in patients with OCD, and it appears that the VOCI scores were correspondingly stable. However, the sample available for test-retest reliability analysis was small $(n=28)$, and thus the true test-retest reliability may be somewhat different because of sampling error. In the student sample, the test-retest reliability coefficients were low, indicating relatively poor test-retest reliability in this sample. This may have been due to measurement error, that is, an actual problem with the reliability of the scale; however, the high internal consistency of the subscales within the student sample would suggest that this is unlikely to be the major cause of the low test-retest reliability estimates. Instead, the likely cause of the low reliability estimates is range restriction (i.e., the maximum possible correlation coefficient may have 
been significantly degraded because of the restricted range of responses in the student sample). Examination of a scatterplot of the $\mathrm{VOCI}$ mean item score and retest $\mathrm{VOCI}$ mean item score in the student sample showed that the majority of participants were clustered between 0 and 1 (recall that the items are scored from 0 to 4 ), with approximately 4 outliers; this indicates that there may be attenuation in the correlation coefficient due to sample range restriction, caused by a substantial floor effect. This finding suggests that the $\mathrm{VOCl}$ may not be a suitable measure of the low levels of obsessive-compulsive symptoms seen in non-clinical samples. However, it remains to be seen whether the VOCI will be useful in screening non-clinical samples for participants who score towards the clinical range, thus making the VOCI useful in analogue OCD research.

There was evidence of good known-groups validity for the VOCI Total score, as well as the subscales for Contamination, Checking, and Just Right. For these scales, the OCD group scored significantly higher than each of the control groups. This finding indicates that these scales are measuring phenomena characteristic of OCD patients. For the Obsessions and Hoarding subscales, the OCD participants did not score significantly higher than the Anxiety/Depression control participants. This finding raised the question of whether these subscales were valid measures of the relevant constructs, whether these constructs occurred in other groups and therefore were not OCD-specific, or whether the OCD sample as a whole scored relatively low on these subscales because of a low frequency of repugnant obsessions and hoarding in the OCD sample. When participants in the sample with Obsessions were identified (based on their YBOCS interview, not questionnaire scores), these participants were found to have scored significantly higher than the rest of the OCD sample, supporting the validity of the Obsessions subscale. We found the same result for Hoarding, again supporting its known-groups validity. Thus, it appeared that the lack of discrimination between the OCD sample and the A/D control sample for the Obsessions and Hoarding subscales was due to the low scores on these subscales in the OCD sample as a whole, most of whom did not have symptoms in these two domains. In summary, there was evidence of good known-groups validity for the $\mathrm{VOCl}$ total and its subscales, with the exception of the Indecisiveness subscale.

For the Indecisiveness subscale, OCD participants scored significantly higher than adult and student controls, but not significantly higher than A/D controls. Because indecisiveness is not closely 
associated with any major subtypes of $O C D$, it was not possible to conduct a known-groups validity examination within the OCD sample. It is possible that the Indecisiveness scale is measuring a construct that is related to OCD, but not necessarily specific to OCD. In other words, the scale may be measuring not only the indecisiveness that is widely recognized and can be devastating to some patients with OCD, but also the indecisiveness that is characteristic for patients with other types of problems, such as depression and generalized anxiety. Indeed, as mentioned above, difficulty making decisions is a diagnostic symptom of a major depressive episode according to DSM-IV criteria. Within the OCD sample, Indecisiveness was significantly related to BDI and BAI scores, indicating that it is related to current depression and anxiety, and within the student sample, Indecisiveness was highly associated with worry and Neuroticism. In summary, while the Indecisiveness subscale may be measuring an important construct for OCD sufferers, it also appears to measure a construct that is related to depression and anxiety in general. Further research is required to determine whether this scale is too general to warrant inclusion in a measure of OCD symptoms; it would be important to know whether it detects the paralyzing indecisiveness associated with some patients with $O C D$, above and beyond the indecisiveness associated with general anxiety and depression.

There was also support for the convergent validity of the VOCI Total score and its subscales. In both OCD participants and students, the $\mathrm{VOCl}$ total score was highly correlated with the $\mathrm{PI}$ and $\mathrm{MOCl}$ total scores, two established measures of OCD phenomena. In addition, for the subscales with clear corresponding subscales in the other measures (Contamination, Checking, and to a lesser extent Obsessions), there were high and significant correlations with the corresponding subscales in the different samples. For the Contamination subscale may be due at least in part to significant item content overlap between VOCl-Contamination and Padua-Contamination; 6 of the $12 \mathrm{VOCl}$ contamination items have similar Padua counterparts. However, only the 2 of the 6 VOCl-Checking and 1 of the $12 \mathrm{VOCl}-$ Obsessions items have close Padua counterparts. The VOCI scales tended to be uncorrelated with personality variables in the OCD sample, but correlated with Neuroticism in the student sample, which itself could be considered an indication of convergent validity: in normal participants, obsessivecompulsive phenomena, as well as other indices of anxiety or depression, would be expected to be associated with trait neuroticism. 
This study also presented evidence for the discriminant validity of the $\mathrm{VOCl}$ and its subscales. While the $\mathrm{VOCI}$ scales did tend to be correlated with depression and anxiety, the VOCl-PI correlation coefficient was significantly higher than the VOCI-BDI correlation coefficient in both OCD and student samples. In addition, the VOCI-MOCI and VOCI-YBSR correlations were significantly higher than VOClBDI correlation for the OCD sample. Thus, there was strong, although not definitive, evidence for the convergent and discriminant validity of the $\mathrm{VOCl}$ scales; they appear to be measuring constructs related to $O C D$, and similar to the well-established self-report measures of OCD, as opposed to general anxiety or depression.

The self-report YBOCS was highly correlated with the VOCI. This finding suggests that correlations among all of the self-report measures, both of OCD and non-OCD psychopathology, may have been inflated due to common method variance (i.e., the self-report format). In addition, all of the self-report psychopathology scales with the exception of the $\mathrm{MOCl}$ contain only items that are positively cued for OCD, so response biases could be further inflating the correlation coefficients. In order to systematically evaluate reliability, convergent validity, and discriminant validity, without the correlationinflating effects of common method variance, Campbell and Fiske (1959) proposed the multitraitmultimethod matrix, in which at least two traits (e.g., OCD and depression) are measured via at least two different methods (e.g., self-report and interview). In the case of the $\mathrm{VOCl}$, one could conduct a multitraitmultimethod analysis using self-report measures of OCD and depression (VOCI and $\mathrm{BDI}$ ) as well as interview measures of OCD and depression (YBOCS and Hamilton Depression Rating Scale).

This strategy may not be useful for evaluating the $\mathrm{VOCl}$ total score against the interview-based YBOCS total score, as the VOCI total score, at least within this OCD sample, appears to have a very low correlation with YBOCS total score, and may be a poor measure of symptom severity in this group. On the other hand, one could use this strategy to investigate individual subscales of the $\mathrm{VOCl}$, where there are interview measures of similar constructs. For example, the DYBOCS described earlier, as well as providing a global severity score, also yields severity scores for several dimensions of OCD symptoms (hence its name, the Dimensional YBOCS). These dimensions include contamination/cleaning, hoarding, and symmetry/ordering/counting/arranging; thus, the DYBOCS has potential for evaluation of the validity of the $\mathrm{VOCl}$ subscales of Contamination, Hoarding, and Just Right. 
Another important area of further evaluation for the $\mathrm{VOCl}$ is to examine its sensitivity to treatment effects, particularly in comparison with other measures of OCD, both self-report and interview. The YBOCS was designed to measure symptom change for treatment outcome trials, and has been considered the gold standard for OCD treatment outcome research. While the MOCI has been shown to be sensitive to changes with treatment (see Taylor, 1998), we hope that the VOCl, with a more flexible item response format, will be more sensitive. The sensitivity of the revised Padua Inventory to treatment effects has yet to be established (see, Taylor, Thordarson, \& Söchting, 2000),

In further research, we may continue to develop scales, written in a similar format to the VOCI (so they could be easily administered together), for domains of OCD symptoms that are not well represented by the VOCl. One example that has already been completed is the Symmetry, Ordering and Arranging Questionnaire (SOAQ; Radomsky \& Rachman, in press). Other useful subscales would include doubts and mental neutralizing. Further research is also required to establish the convergent validity of the VOCI with non-self report measures of OCD symptoms, such as interviewer ratings or peer ratings. Finally, we have yet to evaluate whether the $\mathrm{VOCl}$ is sensitive to treatment-related changes in OCD symptoms. Given the cognitive and behavioural composition of the $\mathrm{VOCl}$, it is well suited for use in assessing the effects of psychological treatments, especially cognitive behaviour therapy.

In conclusion, the $\mathrm{VOCl}$ is a promising new instrument for the assessment of a wide range of obsessional compulsive complaints. Evidence has been presented of its reliability and validity. Further research will help to clarify its factor structure in OCD and non-clinical populations, as well as its utility for treatment-outcome and analogue research. 


\section{Endnotes}

${ }^{1}$ This participant had a diagnosis of anxiety disorder not otherwise specified rather than OCD, but had been included in the OCD treatment study as a pilot participant.

${ }^{2}$ Using the BDI to eliminate participants has the effect of slightly restricting the range of BDI scores, thus attenuating the correlations to some degree. However, this practice appears reasonable given that a range of 0-20 for nonclinical samples is substantial, and in fact, the presence of high BDI scores would otherwise distort the results.

${ }^{3}$ Although they do not perfectly correspond, the types of complaints represented by Orderers are most consistent with the Just Right subscale.

${ }^{4}$ Comparisons among correlation coefficients were limited to this set of comparisons in order to control inflation in family-wise Type I error that would result from making a large number of comparisons. 


\section{Acknowledgements}

This article is based on the doctoral thesis of the first author, conducted in the Department of Psychology, University of British Columbia, under the supervision of Dr. A. Ralph Hakstian and Dr. S. Rachman.

The data for these projects were obtained through the assistance and cooperation of several clinical and research units. We would like to acknowledge and thank the following for their contribution:

Table 1 Anxiety and Fear Laboratory, Department of Psychology, UBC: Nichole Fairbrother, Dave Hammond, Diane Sirkia, and Jackie Gruther-Andrews. Financial support from the British Columbia Health Research Foundation.

Table 1 Anxiety Disorders Unit, UBC Hospital: Dr. Peter McLean, Dr. Maureen Whittal, Maria Watson, and all the volunteers. Financial support from the Medical Research Council of Canada and the Vancouver Hospital and Health Sciences Centre.

Table 1 Traumatic Stress Clinic, Department of Psychiatry, UBC: Dr. Steven Taylor, Angela Yeh, Kate Corcoran, Kathy Eugster, and Colleen Janzen. Financial support from the ObsessiveCompulsive Foundation.

Table 1 Harbor View Mercy Hospital, Fort Smith, Arkansas: Dr. Larry Withers. 


\section{References}

Antony, M. M., Purdon, C., Swinson, R. P., \& Downie, F. (1997, November). Beck Anxiety Inventory Across the Anxiety Disorders and Individuals from a Community Sample. Poster presented at the annual convention of the Association for Advancement of Behavior Therapy, Miami Beach.

Beck, A. T., Epstein, N., Brown, G., \& Steer, R. A. (1988). An inventory for measuring clinical anxiety: Psychometric properties. Journal of Consulting and Clinical Psychology, 56, 893-897.

Beck, A. T., \& Steer, R. A. (1993a). Manual for the Beck Depression Inventory. San Antonio, TX: Psychological Corporation.

Beck, A. T., \& Steer, R. A. (1993b). Manual for the Beck Anxiety Inventory. San Antonio, TX: Psychological Corporation.

Beck, A. T., Steer, R. A., \& Garbin, M. G. (1988). Psychometric properties of the Beck Depression Inventory: Twenty-five years of evaluation. Clinical Psychology Review, 8, 77-100.

Burns, G. L., Keortge, S. G., Formea, G. M., \& Sternberger, L. G. (1996). Revision of the Padua Inventory for obsessive compulsive disorder symptoms: Distinctions between worry, obsessions, and compulsions. Behaviour Research and Therapy, 34, 163-173.

Calamari, J. E., Wiegartz, P. S., \& Janeck, A. S. (1999). Obsessive-compulsive disorder subgroups: A symptom-based clustering approach. Behaviour Research and Therapy, 37, 113-125.

Campbell, D. T., \& Fiske, D. W. (1959). Convergent and discriminant validation by the multitraitmultimethod matrix. Psychological Bulletin, 56, 81-105.

DiNardo, P., Brown, T. A., \& Barlow, D. H. (1994). Anxiety Disorders Interview Schedule for DSM-IV. San Antonio, TX: Graywind Publications/Psychological Corporation.

Emmelkamp, P. M. G. (1988). Maudsley Obsessional-Compulsive Inventory. In M. Hersen \& A. S. Bellack (Eds.), Dictionary of behavioral assessment techniques (pp. 294-296). New York: Pergamon.

Emmelkamp, P. M. G., Kraaijkamp, H. J. M., \& van den Hout, M. A. (1999). Assessment of obsessivecompulsive disorder. Behavior Modification, 23, 269-279.

Eysenck, H. J., \& Eysenck, S. B. G. (1983). Recent advances in the cross-cultural study of personality. In J. N. Butcher \& C. D. Speilberger (Eds.), Advances in personality assessment 2. Hillsdale, NJ: LEA.

First, M. B., Spitzer, R. L., Gibbon, M., \& Williams, J. B. W. (1997). Structured Clinical Interview for DSMIV Axis I Disorders-Patient edition (April 1997 revision). New York: Biometrics Research Department, New York State Psychiatric Institute.

Foa, E. B., Kozak, M. J., Salkovskis, P. M., Coles, M. E., \& Amir, N. (1998). The validation of a new obsessive-compulsive disorder scale: The Obsessive-Compulsive Inventory. Psychological Assessment, 10, 206-214.

Frost, R. O., \& Gross, R. C. (1993). The hoarding of possessions. Behaviour Research and Therapy, 31, 367-381.

Goodman, W., K., Rasmussen, S. A., Price, L H., Mazure, C., Heninger, G. R., \& Charney, D. S. (1989). Yale-Brown Obsessive Compulsive Scale (Y-BOCS). Unpublished manual. 
Hodgson, R. J., \& Rachman, S. (1977). Obsessional-compulsive complaints. Behaviour Research and Therapy, 15, 389-395.

Leckman, J., Grice, D. E., Boardman, J., Zhang, H., Vitale, A., Bondi, C., et al. (1997). Symptoms of obsessive-compulsive disorder. American Journal of Psychiatry, 154, 911-917.

Meng, X. L., Rosenthal, R., \& Rubin, D. B. (1992). Comparing correlated correlation coefficients. Psychological Bulletin, 111, 172-175.

Meyer, T. J., Miller, M. L., Metzger, R. L., \& Borkovec, T. D. (1990). Development and validation of the Penn State Worry Questionnaire. Behaviour Research and Therapy, 28, 487-495.

Rachman, S., \& Hodgson, R. J. (1980). Obsessions and compulsions. Englewood Cliffs NJ: Prentice Hall.

Rachman, S., Thordarson, D. S., \& Radomsky, A. S. (1995, July). A revision of the Maudsley Obsessional Compulsive Inventory. Poster presented at the World Congress of Cognitive and Behavioral Therapies, Copenhagen.

Rachman, S., Thordarson, D. S., Shafran, R., \& Woody, S. R. (1995). Perceived responsibility: Structure and significance. Behaviour Research and Therapy, 33, 779-784.

Radomsky, A. S., \& Rachman, S. (in press). Symmetry, ordering and arranging compulsive behaviour. Behaviour Research and Therapy.

Richter, M. A., Cox, B. J., \& Direnfeld, D. M. (1994). A comparison of three assessment instruments for obsessive-compulsive symptoms. Journal of Behaviour Therapy and Experimental Psychiatry, 25, 143-147.

Sanavio, E. (1988). Obsessions and compulsions: The Padua Inventory. Behaviour Research and Therapy, 26, 169-177.

Shafran, R., Thordarson, D. S., \& Rachman, S. (1996). Thought-action fusion in obsessive compulsive disorder. Journal of Anxiety Disorders, 10, 379-391.

Steketee, G., Frost, R., \& Bogart, K. (1996). The Yale-Brown Obsessive Compulsive Scale: Interview versus self-report. Behaviour Research and Therapy, 34, 675-684.

Taylor, S. (1998). Assessment of obsessive-compulsive disorder. In R. P. Swinson, M. M. Antony, S. Rachman, \& M. A. Richter (Eds.), Obsessive-compulsive disorder: Theory, research, and treatment (pp. 229-257). New York: Guilford.

Taylor, S., Thordarson, D. S., \& Söchting, I. (2002). Obsessive-compulsive disorder. In M. M. Antony and D. H. Barlow (Eds.), Handbook of assessment and treatment planning for psychological disorders (pp. 182-214). New York: Guilford.

Turner, S. M., Beidel, D. C., \& Stanley, M. A. (1992). Are obsessional thoughts and worry different cognitive phenomena? Clinical Psychology Review, 12, 257-270.

Warren, R., Zgourides, G., \& Monto, M. (1993). Self-report versions of the Yale-Brown ObsessiveCompulsive Scale: An assessment of a sample of normals. Psychological Reports, 73, 574. 
Table 1

Demographics

\begin{tabular}{lcccc}
\hline & OCD & $\begin{array}{c}\text { Anxiety/Depression } \\
\text { Control }\end{array}$ & Community Adults & Students \\
\hline $\mathrm{N}$ & 88 & 60 & 39 & \\
$\%$ Female & $63 \%$ & $60 \%$ & $64 \%$ & $69 \%$ \\
M Age & 35.3 & 36.0 & 41.0 & 19.9 \\
M Years Education & 14.6 & 14.3 & 15.7 & 14.1 \\
\hline
\end{tabular}


Table 2

Oblique Primary-Factor Pattern Matrix from the VOCI Factor Analysis: 6-Factor Solution in OCD Sample

\begin{tabular}{|c|c|c|c|c|c|c|c|}
\hline Item \# & Factor 1 & Factor 2 & Factor 3 & Factor 4 & Factor 5 & Factor 6 & $h^{2}$ \\
\hline 18 & .740 & .121 & & & & -.105 & .628 \\
\hline 55 & .718 & .178 & -.106 & & -.227 & .138 & .715 \\
\hline 14 & .713 & & -.125 & -.114 & & -.157 & .597 \\
\hline 53 & .711 & & & & & & .529 \\
\hline 47 & .655 & & -.194 & & & & .546 \\
\hline 19 & .616 & & & & & & .438 \\
\hline 5 & .571 & & & .158 & & -.178 & .486 \\
\hline 24 & .566 & & -.246 & & & & .425 \\
\hline 1 & .464 & & -.214 & -.106 & -.328 & -.105 & .535 \\
\hline 38 & .409 & & & & -.295 & & .349 \\
\hline 9 & .316 & & .104 & .259 & -.234 & & .334 \\
\hline 36 & .258 & & .180 & & -.189 & -.232 & .238 \\
\hline 21 & & .798 & & & & .215 & .656 \\
\hline 23 & -.194 & .793 & -.114 & & & -.171 & .731 \\
\hline 50 & & .773 & & & -.126 & & .678 \\
\hline 39 & & .766 & & .222 & & .106 & .658 \\
\hline 15 & & .721 & & & .110 & & .509 \\
\hline 8 & -.178 & .711 & & & -.150 & & .565 \\
\hline 25 & & .670 & & & -.152 & & .474 \\
\hline 3 & & .630 & & .122 & .156 & -.148 & .497 \\
\hline 13 & & .617 & & -.147 & .132 & & .410 \\
\hline 44 & .310 & .558 & & -.143 & & & .453 \\
\hline 32 & .104 & .540 & -.180 & & .267 & -.135 & .444 \\
\hline 49 & -.246 & .382 & & .263 & -.257 & -.262 & .462 \\
\hline 10 & & & -.814 & .144 & & & .652 \\
\hline 45 & & -.123 & -.785 & & -.137 & & .705 \\
\hline 51 & .131 & & -.784 & & & .130 & .660 \\
\hline 35 & & & -.727 & -.119 & & -.268 & .695 \\
\hline 22 & & & -.722 & & -.181 & -.196 & .714 \\
\hline 26 & & & -.719 & & & & .528 \\
\hline 42 & & .136 & -.704 & & & -.127 & .685 \\
\hline 52 & & & & .795 & & & .596 \\
\hline 16 & & & & .739 & .148 & & .507 \\
\hline 40 & -.121 & & & .709 & & .123 & .504 \\
\hline 27 & & 191 & & .661 & -.195 & & .623 \\
\hline 12 & & 190 & & .614 & & & .438 \\
\hline 2 & & -.156 & & .558 & -.176 & & .392 \\
\hline 54 & & -.148 & -.131 & .558 & .166 & -.159 & .401 \\
\hline 46 & .164 & & & .549 & & & .342 \\
\hline 6 & & & -.162 & .510 & -.157 & -.242 & .553 \\
\hline 34 & & & & .471 & -.108 & -.287 & .444 \\
\hline 30 & .131 & & & .395 & -.130 & -.144 & .325 \\
\hline 28 & & & & .356 & & -.208 & .240 \\
\hline
\end{tabular}


Table 2 continued

\begin{tabular}{lccccccc}
\hline Item \# & Factor 1 & Factor 2 & Factor 3 & Factor 4 & Factor 5 & Factor 6 & $h^{2}$ \\
\hline 43 & & & & & -.903 & & .889 \\
7 & & & & -.903 & -.108 & .829 \\
33 & .124 & & & -.857 & & .795 \\
41 & .280 & & & -.812 & & .865 \\
20 & & .108 & -.101 & & -.811 & & .760 \\
37 & & -.161 & & & -.810 & & .713 \\
\hline 17 & & & & & & -.844 & .832 \\
11 & & & -.224 & & & -.765 & .661 \\
4 & .149 & .115 & -.196 & .124 & & -.627 & .687 \\
48 & .283 & & & .133 & & -.462 & .442 \\
29 & .120 & & .223 & & -.124 & -.318 & .203 \\
31 & & & & & & & \\
\hline
\end{tabular}

Note. Factor loadings less than \pm .1 were omitted from the table. $h^{2}=$ communalities. 
Table 3

Factor Correlation Matrix: 6-Factor Solution

\begin{tabular}{l|cccccc}
\hline Factor & 1 & 2 & 3 & 4 & 5 & 6 \\
\hline 1 & 1.000 & .114 & -.167 & .151 & -.301 & -.333 \\
2 & .114 & 1.000 & -.113 & .114 & -.105 & -.179 \\
3 & -.167 & -.113 & 1.000 & -.056 & .113 & .183 \\
4 & .151 & .114 & -.056 & 1.000 & -.247 & -.275 \\
5 & -.301 & -.105 & .113 & -.247 & 1.000 & .210 \\
6 & -.333 & -.179 & .183 & -.275 & .210 & 1.000 \\
\hline
\end{tabular}

Note. Factor 1: Just Right; Factor 2: Contamination; Factor 3: Hoarding; Factor 4: Obsessions; Factor 5:

Checking; Factor 6: Indecisiveness 
Table 4

Items from the Vancouver Obsessional Compulsive Inventory (VOCI) arranged by subscales

\begin{tabular}{|c|c|}
\hline \multicolumn{2}{|l|}{ Contamination } \\
\hline 3 & I feel very dirty after touching money. \\
\hline 8 & I use an excessive amount of disinfectants to keep my home or myself safe from germs. \\
\hline 13 & I spend far too much time washing my hands. \\
\hline 15 & Touching the bottom of my shoes makes me very anxious. \\
\hline 21 & I find it very difficult to touch garbage or garbage bins. \\
\hline 23 & I am excessively concerned about germs and disease. \\
\hline 25 & I avoid using public telephones because of possible contamination. \\
\hline 32 & I feel very contaminated if I touch an animal. \\
\hline 39 & $\begin{array}{l}\text { I am very afraid of having even slight contact with bodily secretions (blood, urine, sweat, } \\
\text { etc.). }\end{array}$ \\
\hline 44 & One of my major problems is that I am excessively concerned about cleanliness. \\
\hline 49 & I often experience upsetting and unwanted thoughts about illness. \\
\hline 50 & I am afraid to use even well kept public toilets because I am so concerned about germs. \\
\hline \multicolumn{2}{|l|}{ Checking } \\
\hline 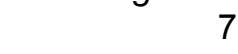 & I repeatedly check and recheck things like taps and switches after turning them off. \\
\hline 20 & $\begin{array}{l}\text { I repeatedly check that my doors or windows are locked, even though I try to resist the } \\
\text { urge to do so. }\end{array}$ \\
\hline 33 & One of my major problems is repeated checking. \\
\hline 37 & I repeatedly check that my stove is turned off, even though I resist the urge to do so. \\
\hline 41 & I spend a lot of time every day checking things over and over again. \\
\hline 43 & $\begin{array}{l}\text { I frequently have to check things like switches, faucets, appliances, and doors several } \\
\text { times. }\end{array}$ \\
\hline \multicolumn{2}{|l|}{ Obsessions } \\
\hline 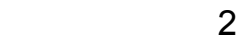 & I am often upset by my unwanted thoughts of using a sharp weapon. \\
\hline 6 & I repeatedly experience the same unwanted thought or image about an accident. \\
\hline 12 & $\begin{array}{l}\text { I find that almost every day I am upset by unpleasant thoughts that come into my mind } \\
\text { against my will. }\end{array}$ \\
\hline 16 & I am often upset by my unwanted thoughts or images of sexual acts. \\
\hline 27 & I repeatedly experience the same upsetting thought or image about death. \\
\hline 28 & $\begin{array}{l}\text { I am often upset by unwanted thoughts or images of blurting out obscenities or insults in } \\
\text { public. }\end{array}$ \\
\hline 30 & I am often frightened by unwanted urges to drive or run into oncoming traffic. \\
\hline 34 & I often experience upsetting and unwanted thoughts about losing control. \\
\hline 40 & I am often very upset by my unwanted impulses to harm other people. \\
\hline 46 & I repeatedly experience upsetting and unacceptable thoughts of a religious nature. \\
\hline 52 & I repeatedly experience upsetting and unwanted immoral thoughts. \\
\hline 54 & I am often upset by unwanted urges to harm myself. \\
\hline \multicolumn{2}{|l|}{ Hoarding } \\
\hline 10 & $\begin{array}{l}\text { I have trouble carrying out normal household activities because my home is so cluttered } \\
\text { with things I have collected. }\end{array}$ \\
\hline 22 & I become very tense or upset when I think about throwing anything away. \\
\hline 26 & $\begin{array}{l}\text { I am embarrassed to invite people to my home because it is full of piles of worthless } \\
\text { things I have saved. }\end{array}$ \\
\hline 35 & I find it almost impossible to decide what to keep and what to throw away. \\
\hline 42 & I have great trouble throwing anything away because I am very afraid of being wasteful. \\
\hline 45 & $\begin{array}{l}\text { I feel compelled to keep far too many things like old magazines, newspapers, and } \\
\text { receipts because I am afraid I might need them in the future. }\end{array}$ \\
\hline 51 & Although I try to resist, I feel compelled to collect a large quantity of things I never \\
\hline
\end{tabular}


actually use.

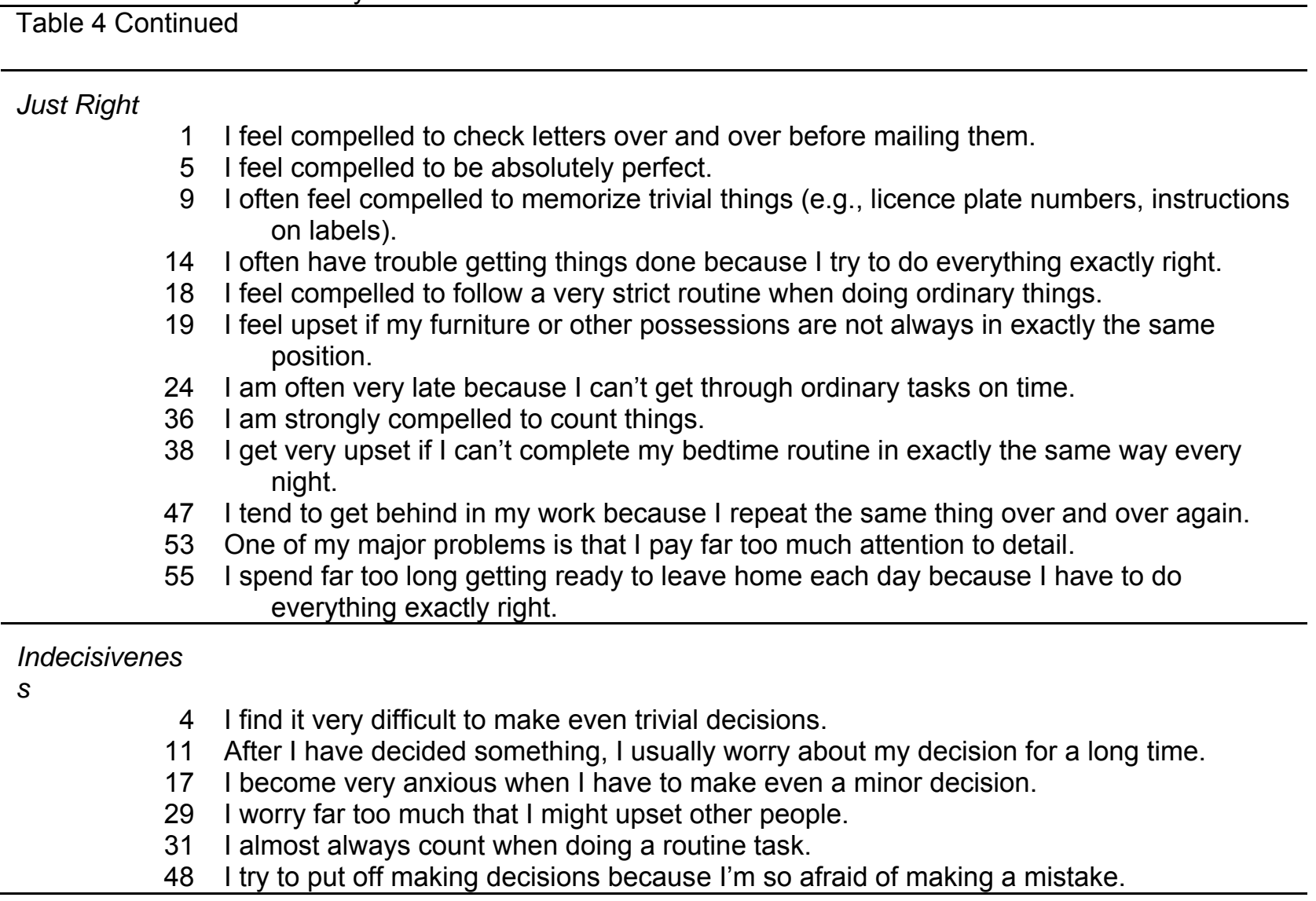

Note. A copy of the $\mathrm{VOCl}$ questionnaire form is available; please contact the first author. Each item is rated 0 (not at all), 1 (a little), 2 (some), 3 (much), or 4 (very much) in response to the prompt, How much is each of the following statements true of you? Total score and subscales are computed by summing the items. 
Table 5

Test-Retest Reliability: VOCI Total and Subscales

\begin{tabular}{lcc}
\hline & \multicolumn{2}{c}{ Test-Retest Reliability } \\
\cline { 2 - 3 } & OCD $(n=28)$ & Students $(n=28)$ \\
\hline Mean Test-retest interval & 47 days & 11 days \\
\hline VOCI Total & $.96^{* *}$ & $.52^{*}$ \\
Contamination & $.97^{* *}$ & $.53^{*}$ \\
Checking & $.96^{* *}$ & $.59^{* *}$ \\
Obsessions & $.91^{* *}$ & $.60^{* *}$ \\
Hoarding & $.96^{* *}$ & $.56^{*}$ \\
Just Right & $.91^{* *}$ & $.54^{*}$ \\
Indecisiveness & $.90^{* *}$ & $.50^{*}$ \\
\hline
\end{tabular}

${ }^{* *} p<.001 .{ }^{*} p<.01$.

Note. For OCD group, one-sided .95 confidence intervals all $\geq .81$. For students, one-sided .95 confidence intervals all $\geq .22$. 
Table 6

Internal Consistency: VOCI Total and Subscales

\begin{tabular}{|c|c|c|c|c|}
\hline & OCD & $\begin{array}{c}\text { Anxiety/ } \\
\text { Depression }\end{array}$ & $\begin{array}{c}\text { Community } \\
\text { Adults }\end{array}$ & Students \\
\hline VOCI Total & .94 & .98 & .90 & .96 \\
\hline 55 items & $(n=80)$ & $(n=57)$ & $(n=37)$ & $(n=189)$ \\
\hline Contamination & .92 & .92 & .79 & .87 \\
\hline 12 items & $(n=85)$ & $(n=59)$ & $(n=39)$ & $(n=198)$ \\
\hline Checking & .96 & .94 & .70 & .92 \\
\hline 6 items & $(n=88)$ & $(n=60)$ & $(n=39)$ & $(n=198)$ \\
\hline Obsessions & .88 & .93 & .70 & .88 \\
\hline 12 items & $(n=86)$ & $(n=59)$ & $(n=39)$ & $(n=198)$ \\
\hline Hoarding & .92 & .90 & .80 & .85 \\
\hline 7 items & $(n=88)$ & $(n=60)$ & $(n=38)$ & $(n=197)$ \\
\hline Just Right & .89 & .91 & .81 & .87 \\
\hline 12 items & $(n=85)$ & $(n=60)$ & $(n=39)$ & $(n=197)$ \\
\hline Indecisiveness & .85 & .90 & .79 & .83 \\
\hline 6 items & $(n=88)$ & $(n=59)$ & $(n=38)$ & $(n=200)$ \\
\hline
\end{tabular}


Table 7

Means and Standard Deviations for VOCI Total and Subscale Scores by Groups

\begin{tabular}{|c|c|c|c|c|}
\hline VOCI Subscale & $\begin{array}{l}\text { OCD } \\
n=88\end{array}$ & $\begin{array}{l}\text { Anxiety/ } \\
\text { Depression } \\
\quad n=60\end{array}$ & $\begin{array}{l}\text { Community Adults } \\
\qquad n=39\end{array}$ & $\begin{array}{l}\text { Students } \\
n=200\end{array}$ \\
\hline VOCI Total & $\begin{array}{c}86.26 \\
(37.47)\end{array}$ & $\begin{array}{l}49.61^{*} \\
(43.28)\end{array}$ & $\begin{array}{l}11.45^{*} \\
(10.85)\end{array}$ & $\begin{array}{l}36.37^{*} \\
(26.56)\end{array}$ \\
\hline Contamination & $\begin{array}{c}19.41 \\
(12.51)\end{array}$ & $\begin{array}{l}7.10^{*} \\
(8.96)\end{array}$ & $\begin{array}{l}1.74^{*} \\
(2.94)\end{array}$ & $\begin{array}{l}7.31^{*} \\
(6.82)\end{array}$ \\
\hline Checking & $\begin{array}{l}12.32 \\
(8.62)\end{array}$ & $\begin{array}{l}3.88^{*} \\
(5.37)\end{array}$ & $\begin{array}{l}0.79^{*} \\
(1.51)\end{array}$ & $\begin{array}{l}3.16^{*} \\
(4.27)\end{array}$ \\
\hline Obsessions & $\begin{array}{c}12.63 \\
(10.55)\end{array}$ & $\begin{array}{c}11.47 \\
(11.98)\end{array}$ & $\begin{array}{l}1.97^{*} \\
(3.03)\end{array}$ & $\begin{array}{l}5.52^{*} \\
(5.97)\end{array}$ \\
\hline Hoarding & $\begin{array}{c}7.74 \\
(7.73)\end{array}$ & $\begin{array}{c}6.20 \\
(6.99)\end{array}$ & $\begin{array}{l}2.16^{*} \\
(2.78)\end{array}$ & $\begin{array}{l}5.61^{*} \\
(4.90)\end{array}$ \\
\hline Just Right & $\begin{array}{c}23.23 \\
(11.63)\end{array}$ & $\begin{array}{l}12.15^{*} \\
(9.89)\end{array}$ & $\begin{array}{l}2.77^{*} \\
(3.49)\end{array}$ & $\begin{array}{l}9.00^{*} \\
(7.06)\end{array}$ \\
\hline Indecisiveness & $\begin{array}{l}10.95 \\
(6.47)\end{array}$ & $\begin{array}{l}8.81^{*} \\
(6.57)\end{array}$ & $\begin{array}{l}2.01^{*} \\
(2.53)\end{array}$ & $\begin{array}{l}5.77^{*} \\
(4.44)\end{array}$ \\
\hline
\end{tabular}

* Indicates means significantly different from OCD mean using the Dunnett method of multiple comparisons, $\alpha<.05$, nondirectional. 
Table 8

Known-Groups Validity: OCD Subtypes

\begin{tabular}{|c|c|c|c|c|}
\hline OCD Subtype & VOCI Subscale & $d f$ & $t$ & $p$ \\
\hline & Contamination & & & \\
\hline Cleaner $(n=49)$ & $M=25.26, S D=11.56$ & 85 & 5.88 & $<.001$ \\
\hline \multirow[t]{2}{*}{ Other OCD $(n=38)$} & $M=11.72, S D=9.36$ & & & \\
\hline & Checking & & & \\
\hline Checker $(n=47)$ & $M=15.60, S D=7.91$ & 85 & 4.26 & $<.001$ \\
\hline \multirow[t]{2}{*}{ Other OCD $(n=40)$} & $M=8.35, S D=7.90$ & & & \\
\hline & Obsessions & & & \\
\hline Obsessional $(n=33)$ & $M=18.55, S D=9.81$ & 85 & 4.68 & $<.001$ \\
\hline \multirow[t]{2}{*}{ Other OCD $(n=54)$} & $M=8.80, S D=9.20$ & & & \\
\hline & Just Right & & & \\
\hline Orderer $(n=36)$ & $M=24.25, S D=11.42$ & 85 & 0.79 & .43 \\
\hline \multirow[t]{2}{*}{ Other OCD $(n=51)$} & $M=22.24, S D=11.78$ & & & \\
\hline & Hoarding & & & \\
\hline Hoarder $(n=11)$ & $M=18.18, S D=8.39$ & 85 & 5.51 & $<.001$ \\
\hline Other $\operatorname{OCD}(n=76)$ & $M=6.33, S D=6.41$ & & & \\
\hline
\end{tabular}


Table 9

Convergent and Discriminant Validity: OCD Sample

\begin{tabular}{|c|c|c|c|c|c|c|c|}
\hline & \multicolumn{7}{|c|}{ VOCI Scale } \\
\hline & Total & Contamination & Checking & Obsessions & Hoarding & Just Right & Indecisiveness \\
\hline PI Total & $.85^{*}(n=87)$ & & & & & & \\
\hline PI Contamination & & $.90^{*}(n=87)$ & $.08(n=87)$ & $.11(n=87)$ & $.16(n=87)$ & $.12(n=87)$ & $.22(n=87)$ \\
\hline PI Dressing & & $.08(n=86)$ & $.30(n=86)$ & $.15(n=86)$ & $.15(n=86)$ & $.62^{*}(n=86)$ & $.15(n=86)$ \\
\hline PI Checking & & $.10(n=87)$ & $.84^{*}(n=87)$ & $.32(n=87)$ & $.34^{*}(n=87)$ & $.67^{*}(n=87)$ & $.45^{\star}(n=87)$ \\
\hline PI Thoughts of Harm & & $.40^{*}(n=87)$ & $.41^{*}(n=87)$ & $.61 *(n=87)$ & $.13(n=87)$ & $.33(n=87)$ & $.49^{*}(n=87)$ \\
\hline PI Impulses to Harm & & $.10(n=86)$ & $.27(n=86)$ & $.55^{*}(n=86)$ & $.19(n=86)$ & $.31(n=86)$ & $.14(n=86)$ \\
\hline MOCI Total & $.74^{*}(n=56)$ & & & & & & \\
\hline MOCI Washing & & $.83^{*}(n=56)$ & $.06(n=56)$ & $.15(n=56)$ & $-.04 \quad(n=56)$ & $.22(n=56)$ & $.12(n=56)$ \\
\hline MOCI Checking & & $.19(n=56)$ & $.81^{*}(n=56)$ & $.66^{*}(n=56)$ & $.30(n=56)$ & $.55^{\star}(n=56)$ & $.38(n=56)$ \\
\hline MOCI Doubting/ & & $.13(n=55)$ & $.33(n=55)$ & $.36(n=55)$ & $.30 \quad(n=55)$ & $.53^{*}(n=55)$ & $.40 \quad(n=55)$ \\
\hline Conscientiousness & & & & & & & \\
\hline MOCI Slowness & & $-.09(n=56)$ & $.12(n=56)$ & $-.01(n=56)$ & $.02(n=56)$ & $.51^{*}(n=56)$ & $.24(n=56)$ \\
\hline YBOCS Interview Total & $.14(n=49)$ & & & & & & \\
\hline $\begin{array}{l}\text { YBOCS Self-report } \\
\text { Total }\end{array}$ & $.67^{*}(n=49)$ & & & & & & \\
\hline BDI & $.47^{*}(n=87)$ & $.22(n=87)$ & $.15(n=87)$ & $.40^{*}(n=87)$ & $.24(n=87)$ & $.33(n=87)$ & $.54^{*}(n=87)$ \\
\hline BAI & $.43^{*}(n=87)$ & $.10(n=87)$ & $.09(n=87)$ & $.49^{*}(n=87)$ & $.25(n=87)$ & $.35^{*}(n=87)$ & $.48^{*}(n=87)$ \\
\hline PSWQ & $.36(n=67)$ & $.10(n=67)$ & $.17(n=67)$ & $.38^{*}(n=67)$ & $-.04 \quad(n=67)$ & $.36(n=67)$ & $.44^{*}(n=67)$ \\
\hline EPQ-R & & & & & & & \\
\hline Neuroticism & $.17(n=33)$ & $.21(n=33)$ & $-.16 \quad(n=33)$ & $.31 \quad(n=33)$ & $.01(n=33)$ & $-.04 \quad(n=33)$ & $.33(n=33)$ \\
\hline Psychoticism & $.02(n=32)$ & $.16 \quad(n=32)$ & $-.05 \quad(n=32)$ & $.10 \quad(n=32)$ & $-.09(n=32)$ & $-.06 \quad(n=32)$ & $-.24(n=32)$ \\
\hline Extraversion & $-.23(n=32)$ & $-.13(n=32)$ & $-.08 \quad(n=32)$ & $-.20(n=32)$ & $-.18 \quad(n=32)$ & $-.08 \quad(n=32)$ & $-.23(n=32)$ \\
\hline Lie Scale & $.06(n=33)$ & $-.13(n=33)$ & $.17(n=33)$ & $-.07 \quad(n=33)$ & $.12(n=33)$ & $.17(n=33)$ & $.09(n=33)$ \\
\hline
\end{tabular}

${ }^{*} p<.001$ 
Table 10

Convergent and Discriminant Validity: Student Sample

\begin{tabular}{|c|c|c|c|c|c|c|c|}
\hline & \multicolumn{7}{|c|}{ VOCI Scale } \\
\hline & Total & Contamination & Checking & Obsessions & Hoarding & Just Right & Indecisiveness \\
\hline PI Total & $.79 *(n=196)$ & & & & & & \\
\hline PI Contamination & & $.85^{*}(n=196)$ & $.39^{*}(n=187)$ & $.38^{*}(n=194)$ & $.51^{*}(n=197)$ & $.59^{*}(n=196)$ & $.45^{*}(n=196)$ \\
\hline PI Dressing & & $.39^{*}(n=193)$ & $.38^{*}(n=185)$ & $.30^{*}(n=192)$ & $.33^{*}(n=195)$ & $.49^{*}(n=194)$ & $.43^{*}(n=194)$ \\
\hline PI Checking & & $.48^{*}(n=193)$ & $.71^{*}(n=186)$ & $.39 *(n=192)$ & $.49^{*}(n=195)$ & $.72^{*}(n=194)$ & $.59^{*}(n=194)$ \\
\hline PI Thoughts of Harm & & $.46^{*}(n=190)$ & $.44^{*}(n=183)$ & $.50^{*}(n=190)$ & $.51^{*}(n=192)$ & $.56^{*}(n=191)$ & $.57^{*}(n=191)$ \\
\hline PI Impulses to Harm & & $.24^{*}(n=190)$ & $.26^{*}(n=182)$ & $.45^{*}(n=190)$ & $.22(n=192)$ & $.27^{*}(n=191)$ & $.15(n=191)$ \\
\hline MOCI Total & $.64^{*}(n=200)$ & & & & & & \\
\hline MOCI Washing & & $.59^{*}(n=198)$ & $.07 \quad(n=190)$ & $.33^{*}(n=197)$ & $.29^{*}(n=200)$ & $.39^{*}(n=199)$ & $.36^{*}(n=199)$ \\
\hline MOCI Checking & & $.43^{*}(n=198)$ & $.45^{*}(n=190)$ & $.43^{*}(n=197)$ & $.35^{*}(n=200)$ & $.57^{*}(n=199)$ & $.44^{*}(n=199)$ \\
\hline MOCI Doubting/ & & $.42^{*}(n=198)$ & $.27^{*}(n=190)$ & $.31^{*}(n=197)$ & $.37^{*}(n=200)$ & $.46^{*}(n=199)$ & $.45^{*}(n=199)$ \\
\hline \multicolumn{8}{|l|}{ Conscientiousness } \\
\hline MOCI Slowness & & $.12(n=198)$ & $.08(n=190)$ & $.03(n=197)$ & $.17(n=200)$ & $.24^{*}(n=199)$ & $.20(n=199)$ \\
\hline BDI & $.43^{*}(n=200)$ & $.27^{\star}(n=198)$ & $.10(n=190)$ & $.40^{*}(n=197)$ & $.43^{*}(n=200)$ & $.35^{\star}(n=199)$ & $.44^{*}(n=199)$ \\
\hline $\mathrm{BAI}$ & $.44^{*}(n=200)$ & $.31^{*}(n=198)$ & $.19^{*}(n=190)$ & $.39 *(n=197)$ & $.34^{*}(n=200)$ & $.38^{*}(n=199)$ & $.44^{*}(n=199)$ \\
\hline PSWQ & $.59^{*}(n=198)$ & $.48^{*}(n=196)$ & $.27^{*}(n=188)$ & $.36^{*}(n=195)$ & $.47^{*}(n=198)$ & $.54^{*}(n=197)$ & $.68^{*}(n=197)$ \\
\hline \multicolumn{8}{|l|}{ EPQR } \\
\hline Neuroticism & $.56^{*}(n=111)$ & $.45^{*}(n=110)$ & $.24^{*}(n=103)$ & $.43^{*}(n=109)$ & $.47^{*}(n=111)$ & $.46^{*}(n=110)$ & $.63^{*}(n=110)$ \\
\hline Psychoticism & $-.12(n=110)$ & $-.10(n=109)$ & $.05(n=102)$ & $.01 \quad(n=108)$ & $-.17(n=110)$ & $-.15(n=109)$ & $-.27 \quad(n=109)$ \\
\hline Extraversion & $-.32^{*}(n=110)$ & $-.14 \quad(n=109)$ & $-.15(n=102)$ & $-.23(n=108)$ & $-.35^{*}(n=110)$ & $-.28 \quad(n=109)$ & $-.38^{*}(n=109)$ \\
\hline Lie Scale & $.11(n=110)$ & $.12(n=109)$ & $.11 \quad(n=102)$ & $.17(n=108)$ & $.06(n=110)$ & $.15(n=109)$ & $.11 \quad(n=109)$ \\
\hline
\end{tabular}

${ }^{*} p<.001$ 